\title{
Contracampo
}

\section{A emergência dos piratas nas redes do capitalismo informacional}

\author{
The rise of pirates in the networks \\ of informational capitalism
}

Rodrigo Saturnino rodrigo.saturnino@gmail.com

Doutor em Sociologia pela Universidade de Lisboa - Instituto de Ciências Sociais (ICS-UL), investigador colaborador do Centro de Estudos das Migrações e das Relações Interculturais da Universidade Aberta (CEMRI-UAB) e bolsista da Fundação para a Ciência e a Tecnologia (FCT).

Ao citar este artigo, utilize a seguinte referência bibliográfica

SATURNINO, Rodrigo. A emergência dos piratas nas redes do capitalismo informacional. In: Revista Contracampo, v. 33, n. 2 , ed. ago-nov, ano 2015. Niterói: Contracampo, 2015. Págs: 63-85.

DOI: 10.5327/Z22382577201500332775

Enviado em: 10 de maio de 2015

Aceito em: 23 de set. de 2015

\section{PPGCOM}

\section{Edição 33 3 2/2015}

Comunicação e Materialidades 2

Contracampo

e-ISSN 2238-2577

Niterói (RJ), v. 33, n. 2, ago-nov/2015

www.uff.br/contracampo

A Revista Contracampo é uma revista eletrônica do Programa de PósGraduação em Comunicação da Universidade Federal Fluminense e tem como objetivo contribuir para a reflexão crítica em torno do campo midiático, atuando como espaço de circulação da pesquisa e do pensamento acadêmico. 


\section{Resumo}

O objetivo deste texto é analisar as identidades políticas dos piratas. A partir da história do movimento dos Partidos Piratas, o artigo investiga como novos ativismos partidários têm vindo a instituir-se ao redor do mundo através de uma reflexividade fundamentada em valores éticos e morais procedentes de utopias tecnológicas antecessoras à sua existência. Ainda no âmbito analítico, discute-se como o imaginário reticular auxiliou a redefinir as regras da economia mundial e as formas de consumo, bem como serviu de suporte mobilizador de novas subjetividades empenhadas na reorganização da geopolítica da rede.

Palavras-chave: internet; partido pirata; rede.

\section{Abstract}

The purpose of this paper is to analyse the political identities of the pirates. From the history of the Pirate Parties Movement, the article investigates how new political activism has been instituted through a reflexivity sustained by ethical and moral values derived by technological utopias that precede their existence. In the analytical frame, it argues that the reticular imaginary helped to redefine the rules of worldwide economy and the forms of consumption, as well as served as a support to mobilize new subjectivities committed to reorganize the geopolitics of network.

Keywords: internet; pirate party; network. 


\section{Introdução}

\section{Informação é poder}

conhecida expressão abre o Guerilla Open Access Manifesto (SWARTZ, 2008) -
uma espécie de versão revisitada da Declaration of the Independence of Cyberspace de Perry Barlow (1996) —, escrito, em 2008, pelo hacker norte-americano Aaron Swartz. A trajetória de vida de Aaron ficou conhecida mundialmente após seu suicídio, cometido no dia 11 de Janeiro de 2013, na sequência da sua condenação à 35 anos de prisão por ter descarregado, através de servidores do Massachusetts Institute of Technology (MIT), milhares de artigos acadêmicos que estavam sob a tutela do Journal Storage (JSTOR) ${ }^{1}$. Swartz, que na época tinha 26 anos, se afirmou como um das mais proeminentes personagens a defender a importância da livre partilha do conhecimento através das redes digitais como um recurso fundamental para o desenvolvimento social. Aaron acreditava que o conhecimento era a chave para uma sociedade melhor. Uma chave que deveria ser partilhada com todo o mundo em contrapartida ao bloqueio que tem sido feito por monopólios editoriais. Partilhar é um imperativo moral; um ato de hombridade contra a privatização do saber. No dizer do hacktivista, a luta pela abertura da Internet exige coragem. Sobrepor as leis que subsidiam a punição daqueles que assentam a sua prática a partir de uma consciência política da informação requer um pensamento que a interprete não apenas como um elemento contemporâneo de estruturação dos poderes, mas como um bem público; um direito a que todos devem, livremente, aceder.

\section{Internet é política}

Embora a tragédia de Aaron tenha sido considerada como consequência de um longo quadro depressivo que o acompanhava, a sua morte foi respondida de modo imediato. As manifestações e protestos se espalharam pelo mundo não apenas porque ele

1 O JSTOR é uma biblioteca digital, fundada em 1995, que comercializa grande parte do material que armazena em seus servidores. O download dos ficheiros do JSTOR teve início no outono de 2010 através de uma conta de um utilizador-convidado. O aumento incomum no tráfego de dados entre os servidores do MIT e do JSTOR chamou a atenção de ambas instituições devido a um suposta sobrecarga no sistema. Uma primeira tentativa foi feita para desabilitar o acesso. Entretanto, a conta foi restaurada. A polícia do Estado de Massachusetts e o Federal Bureau of Investigation (FBI) foram convocados a investigar a situação. Em janeiro de 2011, Aaron Swartz foi detido no campus do MIT (SIMS, 2011; MACFARQUHAR, 2013). 
era jovem, mas porque o seu ativismo representava uma causa internacional: a liberdade na Internet. Muitos são os casos que se juntam ao do programador para reforçar as lutas contemporâneas e os novos protagonismos elaborados a partir das tensões ocasionadas pelas investidas jurídicas de incriminação e intimidação das formas alternativas de consumo e de distribuição de conteúdos (leia-se filmes, músicas, livros, artigos acadêmicos, vídeos, imagens, bases de dados, softwares, etc.) protegidos pelas leis dos direitos de autor e da propriedade intelectual ${ }^{2}$. Esses ativismos, emersos sob a tutela da Internet como espaço para a livre partilha do saber, reiteram como a ambivalência da informação, a elasticidade da ideia de rede e as ambiguidades da pirataria serviram de aportes para prover uma variedade de cisões sociais quer nos setores político, jurídico e econômico, quer nas camadas mais íntimas da vida. No âmbito institucional, a emergência do Partido Pirata em vários países é um dos exemplos mais demonstrativos dessas divergências na atualidade ${ }^{3}$. Nesse sentido, este trabalho propõe o enquadramento desse movimento internacional como um efeito ideologicamente influenciado tanto pelo difusionismo social das tecnologias de comunicação como pela conversão da informação e das redes digitais em importantes eixos de disputa de poder.

Metodologicamente, o texto utiliza a trajetória do Partido Pirata para descrever como os conflitos internacionais no campo da regulação da Internet expandiram as clivagens acerca da rede como um dispositivo transformador, fazendo dela não apenas um espaço catalítico para a dinâmica capitalista (SCHILLER, 2000; 2014), mas também um vórtice de novas identidades políticas e novas formas globais de agenciamento (HANDS, 2011; POSTIGO, 2012). Ainda no âmbito analítico, discute-se como o imaginário reticular auxiliou a redefinição das regras da economia mundial e das formas de consumo, servindo de suporte mobilizador de subjetividades tecnológicas empenhadas na reorganização da geopolítica da rede.

\footnotetext{
2 Ver, por exemplo, os casos de denúncias de Edward Snowden, Julian Assange através do Wikileaks, as intervenções dos Anonymous, e ainda o ativismo de movimentos como o Open Access Movement, Free Software, Open Science, Copyleft, entre outros.

3 No texto, a terminologia "Partido Pirata" serve para identificar os partidos políticos (oficiais e não-oficializados) de diferentes países que partilham causas comuns, como a liberdade da informação e do conhecimento, reforma das leis de direitos autorais e patentes, direito à privacidade, transparência pública, democracia direta, entre outras.
} 


\section{Polissemia, fisionomia e metáforas: as ambivalências da rede}

A ideia de rede, pensada de modo análogo através do pensamento filosófico, desde o século XVII, tem designado diferentes formas representativas da constituição das relações econômicas e sociais (SUBTIL, 2007; MERKLÉ, 2004). Atualmente, o termo é um aparato transdisciplinar utilizado para qualificar tanto um conjunto de estradas como os ajuntamentos de indivíduos (WELLMAN \& BERKOWITZ, 1991). Fala-se em redes ferroviárias, redes elétricas, redes de pesca, redes de investigação, redes sociais, redes informáticas, redes de neurônios, etc.. Apesar das alternâncias aplicativas e da variedade de disciplinas que utilizam o vocábulo, a rede mantém um núcleo comum caracterizado por sistemas complexos de interconexões que tanto podem ser físicas como imaginárias (SFEZ, 2005).

As contribuições de Musso (1999; 2003; 2004; 2013) e Mattelart (1994; 2000) reiteram o caráter epistêmico que a rede adquiriu ao longo da história ocidental ao transitar de um artefato técnico até convergir em um símbolo comunicacional. Tal transformação tem início no final do século XIX por meio da ação de engenheiros e industriais em virtude da proliferação das primeiras redes técnicas (elétricas e ferroviárias) e os seus efeitos no tocante aos avanços econômicos de países como os Estado Unidos. A capacidade da rede em organizar fluxos complexos, diminuir distâncias e interligar espaços facilmente encontrou um lugar distinto na esfera social na medida em que passou a ser revista e reativada como metáfora relevante para desenvolver estratégias de progresso em escalas transnacionais. Para Musso (2013), os movimentos de ressurreição da simbolicidade da arquitetura da rede ao longo da história fundamentaram o seu valor canônico devido às narrativas míticas e parametrizações técnicas que foram sendo elaboradas a respeito da sua eficácia em estruturar a circulação das coisas pertencentes ao mundo da natureza ou do mundo social e em manter o equilíbrio no interior de ambientes de intensa complexidade.

Musso $(2003 ; 2004)$ justifica o advento da rede como uma metáfora contemporânea ao valer-se das incidências sobre o tema encontradas nas hipóteses saint-simonianas e nas teses de Michel Chevalier. Segundo o autor, o modelo racional das redes técnicas serviu de apriorismo científico para dar forma às hipóteses de Claude de Saint-Simon que acreditava nas vias de comunicação (influenciado pela industrialização), como uma condição de vida; um modelo da boa administração e um requisito sine qua non de mudança social (MUSSO, 2004, p. 25; 2013). Na concepção de Saint-Simon, a sociedade deveria 
ser entendida como um organismo vivo trespassado por infinitas redes que o sustenta e o mantém em constante atividade. No organismo-rede ilustrado por Saint-Simon através de uma mistura entre histologia, física dos movimentos e engenharia, o tecido social é constituído por dois tipos de rede: uma material e uma espiritual. A primeira é composta por trocas de energias e matérias-prima, e a segunda, formada para sustentar a vida bancária e o fluxo financeiro (LEMOS, 2005, p. 14-15). Tal interpretação simbólica, elevada por uma fisiologia social assente na releitura do funcionamento dos sistemas orgânicos, pôs em marcha a afirmação virtuosa de que através das redes o mundo transitaria para uma era sem precedentes.

Chevalier, um dos mais proeminentes saint-simonistas, também acreditava que o aprimoramento da comunicação traria benefícios inauditos para uma liberdade real, positiva e prática (MATTELART, 1994, p. 138). Nas Lettres sur l'Amérique du Nord, escritas após a viagem que fez pela América do Norte, México e Cuba entre 1833 e 1835 com o objetivo de estudar as vias de comunicação ${ }^{4}$, salientou como os avanços nos Estados Unidos foram desenvolvidos através da criação da sua malha viária. De modo equivalente, atribuiu às linhas ferroviárias um baluarte perfeito da pleiteada sociedade universal que figurava nas proposições de Saint-Simon (SUBTIL, 2007, p. 103). O encurtamento das distâncias, do tempo e do espaço através da dinâmica das redes conduziria a Europa, principalmente a França, a um avanço proeminente no campo da governança transnacional. Do mesmo modo, traria ao projeto europeu comunitarista a oportunidade de colocar em prática os ideais de igualdade e democracia. O caráter técnico da rede permitiria tanto a comunicação indistinta como também a comunhão e a democratização das coisas através de uma circulação horizontal e igualitária. Não se tratava apenas de reduzir geografias. Importava também diminuir o fosso social entre uma classe e outra. Chevalier, diferente de Saint-Simon, transformou o conceito de rede em um objeto-símbolo, reivindicando o seu desenvolvimento como ícone de uma revolução política urgente e emergente.

Para Musso (2013), a propagação das mitologias em torno da rede e a pujança da sua ideologia ao longo da história estabeleceram a formação de um imaginário retiológico fortemente orientado pelo desejo de equilíbrio, inovação e progresso. No entanto, como

\footnotetext{
${ }^{4}$ A viagem foi realizada por ordem de Adolphe Thiers que, na época, era o Ministro das Obras Públicas da França. As cartas de Chevalier estão disponíveis em: http://gallica.bnf.fr/ark:/12148/bpt6k213749d. Acesso em: 05 fev. 2015.
} 
salientou o autor, a explosão e a polissemia da rede absorveu menos o caráter metafórico e mais o formato técnico, tornando-a em um tipo de prótese para sustentar a busca e a vontade por mudanças estruturais no escopo social. Salienta ainda o filósofo francês que, devido à dupla natureza dos símbolos, tais reavivamentos afirmaram ambivalências representativas que não devem ser desprezadas. A anamorfose da rede como artefato não só modificou a relação social com o espaço e com o tempo, como também cumpriu a função de objetivar, a partir de matrizes técnicas, uma nova condição de vida orientada por benefícios díspares (MUSSO, 2004, p. 35). Ela permite circular, o que faz dela um sistema vivo, orgânico e sanguíneo. No entanto, favorece o controle, a fiscalização e o castigo. Se, de um lado, ela é festejada por proporcionar a livre circulação das coisas, das pessoas e das informações, favorecendo um ambiente utópico de progresso democrático e de melhor transparência pública, por outro lado, a sua matriz técnica é criticada por providenciar mecanismos ideais para a inspeção, para a automatização dos gestos e trajetos, para a comercialização dos afetos e, por conseguinte, para a vigilância generalizada. Estas dualidades enriquecem e desafiam as teorias acerca do papel político da rede. Para os céticos, ela centraliza o poder, aprisiona, cerceia e pune. É o despotismo reticular. Para os otimistas, ela é um instrumento fundamental para o trabalho periférico, para a ação descentralizada e para o trabalho subversivo. É a anarquia na rede. No entanto, o autor ainda reforça que, a par das lutas ideológicas que se travaram na definição da rede, a sua intensa valorização como símbolo de progresso pode favorecer uma lógica do tipo empresarial. Ela é uma nova fonte de lucro ao encarnar-se como eixo de um mercado novo, mundializado, personalizado e acessível a domicílio (MUSSO, 2004, p. 35). É o capitalismo em rede 5 .

Na fisionomia do que o autor denomina de retiologia contemporânea (neologismo criado para caracterizar o vasto conjunto de representações, discursos, imagens e dramatizações utópicas elaboradas a partir de reciclagens epistemológicas e reinterpretações políticas acerca do papel das redes técnicas, especialmente as redes da Internet e da teleinformática),

\footnotetext{
5 Para Mattelart (1994, p. 205), as redes técnicas são configuradas de modo centrípeto. Embora os seus pontos de partida sejam diversos, os de chegada convergem para um pequeno grupo de países. Sobre o assunto, ver a atual cartografia do que autor denominou de "império do cabo", diagramada no fundo do mar a partir do domínio exaustivo das redes de telecomunicações pelas grandes potências mundiais. Os mapas da distribuição de cabos submarinos estão disponíveis em: https://www.telegeography.com/ telecom-maps/index.html. Acesso em 14 abr. 2013.
} 
a rede é reificada e a técnica é fetichizada a partir de visões reconstruídas sob a égide de promessas herdadas do passado em que os aparatos tecnológicos figuravam como meios instrumentais para auxiliar e sustentar as transformações no futuro das sociedades.

\section{Emancipação social e progresso econômico: as promessas da rede}

A elasticidade epistemológica da Internet pensada através das metáforas da rede tem favorecido a formação de variadas paisagens ensaísticas acerca da sua função social. No campo da retiologia contemporânea, as conceptualizações sobre a sociedade em rede e a sua relação frontal com o ciberespaço ainda representam argumentos basilares no sentido de dar a entender o tempo em que se vive. Munidos de metáforas recicladas do legado saint-simoniano, exponentes retiologistas, como Castells (2005), complementam o triunfo da rede através da elaboração de novas leituras teóricas baseadas no funcionamento de organismos naturais e a performance de sistemas artificiais. A fabricação de sensíveis alegorias levadas a cabo por Castells (2005) atribuem à Internet o caráter de coluna vertebral das sociedades contemporâneas e de modo mais dramático a ela é concedida a função mais importante de um sistema orgânico. Nas suas palavras, ela é o "coração de um novo paradigma sociotécnico, (...) a base material de nossas vidas e de nossas formas de relação, de trabalho e de comunicação" (CASTELLS, 2004, p. 287). Em oposição a antigos modelos sociais baseados em paradigmas piramidais ou arborais, centralistas e hierárquicos, o reticular é ubíquo porque permite a existência de estruturas descentralizadas e deshierarquizadas que ultrapassam as finitudes das tentativas anteriores que outrora intentaram promover a organização social (MARTINS, 2011, p. 75).

$\mathrm{Na}$ apreciação de Castells (2005), a afirmação desse modelo (dominante tanto nas economias desenvolvidas como nas em desenvolvimento) foi moldada por cinco características essenciais:

1. a informação é a sua matéria-prima;

2. a penetração das Novas Tecnologias de Comunicação e Informação (NTCIs) no escopo social é inevitável porque a informação é parte integrante da ecologia humana;

3. as NTCIs proporcionam a lógica das redes, única forma material de harmonizar a complexidade das relações; 
4. as NTCIs permitem um contexto de flexibilidade pela sua capacidade recursiva de reorganizar os fluxos;

5. a tecnologia proporciona um ambiente de intensa convergência, conduzindo as trajetórias do seu desenvolvimento como um objetivo comum a diversas disciplinas científicas e à formação de políticas públicas específicas (CASTELLS, 2005, p. 108).

Embora o conceito de sociedade em rede seja discutido a partir de variadas visões (algumas elaboradas por argumentos tecnofóbicos concentrados na moralização da tecnologia como ameaça contra a Natureza e outras, em demasia, por retóricas tecnofílicas, que elogiam de modo célebre o advento da rede mundial de computadores como razão final de retorno à uma comunidade original), é mister considerar que a tecnologia das redes, para além dos seus efeitos rentabilísticos provocou, também, conversões estruturais e impactos na socialidade dos seus utilizadores e, por conseguinte, nas suas respectivas subjetividades (FLORIDI \& SANDERS, 2005). Se a Internet é valorizada enquanto espaço dinamizador das novas subjetividades e, por isso, recomendada como parte essencial dos novos processos de empoderamento e de agenciamento político e cognitivo (ANTOUN \& MALINI, 2013), é também capitulada por raciocínios analíticos que a consideram como um vetor exponencial do progresso e da transformação da economia mundial sendo, desta forma, fortalecida como um espaço maduro para novas tendências do trabalho precário (BRAGA \& ANTUNES, 2009; SCHOLZ, 2013) e para novas formas de consumismo em escalas transnacionais baseadas no caráter imaterial do conhecimento (GORZ, 2003; RIFKIN, 2000).

\section{De sonho reticular à pesadelo tecnológico}

O desenvolvimento das redes de comunicação e a sua acepção como dispositivo de revolução política, por sua vez, conduziu ao que poderia ser chamado de fetichização da informação. No quadro da sua digitalização, passou a ser considerada como uma força elementar da sociedade reticular (BRAMAN, 1989) servindo de aporte providencialista, quase de forma axiomática, para sustentar o amadurecimento do mercado baseado no digital.

Aplicada ao campo da economia, a rede marca o quadro organizativo pelo qual passou os modos de produção. A principal mudança fundamenta-se pela privatização dos serviços 
de telecomunicações a partir de meados de 1950 nos Estados Unidos (SCHILLER, 2000) e pela inclusão da informação na categoria clássica de mercadoria e seu enquadramento como objeto do trabalho (BATES, 1988). A transformação dos diversos símbolos da linguagem humana em códigos binários através da lógica booleana, providenciou a base técnica para reduzir obstáculos epistêmicos e expandir a capacidade mercantil das empresas assentes na informação digital. Mas sendo a informação um elemento imaterial, como atribuir valor econômico a um apriorismo científico que não possuía nenhuma característica da mercadoria típica? A consequência direta do seu traço intangível seria a reprodução, quase de modo infinito, a custo zero. Esta constatação não figurava, de todo, como um incentivo a futuros investidores, a não ser que a ela fosse aplicada a legislação dos direitos autorais e das patentes. Ainda assim, como defendeu Arrow (1984), a questão estaria fadada a constantes constrangimentos e a diversos riscos se considerarmos dois aspectos essenciais: a impossibilidade de garantir propriedade sobre algo empiricamente intangível e a aquisição de um monopólio que contradizia o próprio princípio da exclusividade. Nestas condições, Arrow (1984) concluiu que restava às atividades ligadas à produção e à disseminação da informação tornarem-se públicas.

As conclusões de Arrow (1984) e de outros autores que refletiram sobre a intangibilidade da informação, como Bates (1988), Borgmann (1999), Gorz (2003), Schiller (2000; 2007), Dantas (2003) e Garcia (2006), não impediram o mercado de transformar impossibilidades teóricas em lucros técnicos. Uma das estratégias utilizadas pelos investidores para desenvolver o mercado baseado na informação digital foi estabelecer custos no processo de sua distribuição considerando a dependência de um suporte material para ser partilhada. A Internet ainda representa o melhor exemplo desse processo. Graças à sua arquitetura reticular, à reprodutibilidade técnica da informação e ao desenvolvimento tecnológico, ela permitiu um crescimento econômico exponencial. No entanto, também admitiu que os consumidores participassem no jogo da circulação da informação através do acesso doméstico a potentes computadores conectados em uma rede mundial. O sonho reticular transformou a rede em um pesadelo tecnológico através do que Boyle (2008) denominou de uma "falha" no mercado. Se a rede representa o sistema e a informação, o sangue que nela circula, impedir a sua livre circulação determinaria, então, o colapso prematuro do mercado e o fim da utopia dos retiologistas.

Diante das ambivalências reticulares, as opções para garantir a sobrevida do mercado baseado no digital passaram a afirmar-se através de duas modalidades: uma que 
invoca direitos patrimoniais sobre a informação para, desta forma, justificar a limitação do acesso, a vigilância perene, a incriminação e a punição de consumos não autorizados e outra que vem tentando promover vias de reinvenção do capitalismo informacional a partir da criação de novos modelos de negócio que evitem ou adiem a sua completa destruição. Embora despontem formas criativas de exploração do universo digital no que diz respeito à segunda modalidade, como os casos da distribuição de músicas, filmes e séries televisivas de modo direto (on-demand) através de subscrições por modalidades grátis ou pagas, a primeira opção continua como norma. Nesta ordem de pensamento, a propriedade intelectual aplicada ao contexto da rede, fundamenta-se como uma disciplina legal de privilégios monopolistas que aparenta colocar em risco os interesses públicos defendidos por pessoas como Aaron Swartz, seja através da aplicação inquestionável da lei, da elaboração de tratados internacionais (Trade-Related Aspects of Intellectual Property Rights - TRIPS, Anti-Counterfeiting Trade Agreement - ACTA, Stop Online Piracy ActSOPA, Preventing Real Online Threats to Economic Creativity and Theft of Intellectual Property Act - PIPA) ou por formas sub-reptícias de violação da privacidade, de exclusão social e de limitação técnica do acesso (filtros de dados, suspensão de sites e gestão de direitos digitais - DRM's). Nesse sentido, a informação transfigura-se como atrator político, como um polo mediador de intensificação das disputas entre os valores e as regras, pari passu, do mercado, dos tribunais e dos cidadãos (JORDAN, 2015).

Esta dicotomização da Internet, aparentemente contraditória, tem sido utilizada por uma parte dos estudos críticos da sociologia dos media de modo contestatório a partir de uma orientação clássica que aparenta rejeitar o modo do sistema capitalista e seus desdobramentos, uma vez que as redes digitais, nomeadamente através da exponencialidade da telefonia móvel e da utilização de aplicativos, têm se afirmado como espaço dinamizador de novos modos de produção de valor a partir da comercialização da informação (FUCHS, 2014). Não é raro a tais críticas privar-se de um exercício que interprete as tecnologias das redes apenas por uma via de orientação derrotista apoiada em um tipo de tecnopânico evocado por contextos assimétricos de opressão no qual a figura do sujeito é, heuristicamente, esquecida. Todavia, as tensões ocasionadas pelas disputas de poder que se travam pela sua intensa utilização e pelas diferentes clivagens acerca do seu papel enquanto agente transformador, fazem dela um espaço catalítico para a ação política. Nesta perspectiva, a rede é um elemento fundamental de aceleração das economias mundiais e de impulso na 
formação de novas tendências de trabalho e consumo, como também é vórtice de novas formas de agenciamentos e novas subjetividades em que a figura do sujeito/utilizador tenta catalisar a sua própria força produtiva a partir dos usos e apropriações que faz dela. A reificação da rede, para usar a expressão de Musso (2013), reifica a luta.

\section{Lutas digitais e subjetividades tecnológicas: os conflitos em rede}

As investidas técnicas e jurídicas contra a liberdade de acesso e contra a livre partilha de bens informacionais, por seu turno, serviram de incentivo para o surgimento do primeiro Partido Pirata na Suécia (Piratpartiet), em 2006. A sua recente história foi impulsionada por duas situações ocorridas em 2003: a criação da Swedish Anti-piracy Bureau (Svenka Antipiratbyrån), uma agência privada financiada pela Motion Picture Association of America (MPAA), destinada a salvaguardar a aplicação da lei de direitos autorais no país e o surgimento do Piratbyrån, um coletivo de pessoas dispostas a incluir o debate sobre o copyright na agenda pública a fim de transformá-lo em um problema político (MIEGEL \& OLSSON, 2008; SCIANNAMBLO, 2014). Aproveitando as ameaças políticas concentradas em redor da Internet, Rick Falkvinge criou, em janeiro de 2006, o protótipo do que seria o site do partido através de um hub Direct Connect6. Em dois dias, o site recebeu três milhões de visitas (FALKVINGE, 2013, p. 33). Falkvinge largou o trabalho, fez um empréstimo bancário e decidiu dedicar-se integralmente à construção do partido.

No curso da sua criação, um ataque irruptivo da polícia sueca aos servidores do The Pirate Bay (um tracker ${ }^{7}$ criado pelo Piratbyrån para experimentar a partilha de arquivos indexados em websites utilizando a tecnologia P2P) resultou no aumento da popularidade do Piratpartiet. No entanto, a adesão de milhares de novos membros não significou votos suficientes para vencer a primeira eleição. Na disputa nacional de 2006, o Partido Pirata obteve $0,63 \%$ dos votos. Mesmo sem resultados favoráveis que garantiriam um lugar no Riksdag (Parlamento da Suécia) — mínimo de 4\% —, o Partido tornou-se o terceiro maior

\footnotetext{
Direct Connect é uma rede de partilha de arquivos e de canais de chat.

7 Tracker (BitTorrent tracker) é um servidor que auxilia na comunicação entre dois computadores que utilizam o protocolo de redes peer-to-peer. Um tracker pode operar como um Indexer, ou seja, aquele que também oferece uma lista de ficheiros de partilha. Nenhum dos dois possibilita a descarga direta, como no caso dos cyberlockers, apenas estabelecem o contato entre os pares
} 
fora do Parlamento ultrapassando, por exemplo, o Partido Verde Sueco (ERLINGSSON \& PERSSON, 2011; SCIANNAMBLO, 2014).

Quando foi criado, o alvo principal do Partido Pirata era conduzir o copyright para o debate político, questionando as origens e as formas de legitimidade que o setor privado dispunha para monopolizar a informação e restringir a autonomia civil no exercício de seu direito utilizando, por exemplo, as redes peer-to-peer (P2P). Desse modo, o Piratpartiet passou a enfatizar a releitura de conceitos cruciais para a organização estrutural e legitimação do copyright (como o de autoria e o de propriedade intelectual) à luz do desenvolvimento tecnológico e da afirmação de princípios morais baseados em valores pós-materialistas (MIEGEL \& OLSSON, 2008). Três questões resumiam o seu projeto inicial: Reforma da lei do copyright; abolição do sistema de patentes e respeito pelo direito à privacidade. No mesmo ano de fundação do Partido Pirata da Suécia, ativistas da Áustria, Dinamarca, Alemanha, Finlândia, Irlanda, Polônia, Espanha e Holanda fundaram os próprios partidos a partir da iniciativa de Falkvinge. Em 2015, o número de países a levantarem a bandeira pirata através dos próprios partidos (oficializados e em processo de oficialização) já passa dos sessenta, incluindo países fora da Europa ${ }^{8}$.

A rapidez do seu alastramento fortaleceu o Partido Pirata como um dos mais expressivos fenômenos sociais do século XXI devido ao que poderia ser chamado de franchising ideológico, ou seja, através das réplicas organizacionais criadas nos diferentes contextos culturais, como também pela dinâmica de internacionalização da luta e da disseminação dos repertórios a nível global. No âmbito do desempenho eleitoral, o Partido Pirata não é um caso de sucesso se for comparado às máquinas partidárias tradicionais. No entanto, as vitórias gradativas na Europa indiciam uma progressiva penetração no espectro da política parlamentar9.

Além dos três princípios basilares, a política comum dos Partidos Piratas passou a privilegiar mais dois: a transparência da gestão pública e a construção de uma nova

\footnotetext{
8 No Brasil, o movimento para oficializado do Partido Pirata existe desde 2007. Em 2012, foi fundado na cidade de Recife durante a sua primeira convenção. Na ocasião, foram oficializados a sua estrutura nacional, o estatuto, o programa e as diretrizes do Partido. Em 2013, através de uma campanha coletiva de angariação de fundos, conseguiu arrecadar 20 mil reais para publicar os documentos no Diário Oficial da União (D.O.U.), como prevê a legislação em vigor no país. A publicação foi feita no dia 2 de Setembro de 2013, permitindo à agremiação prosseguir para a fase de recolha de assinaturas, situação em que encontra atualmente.

9 A representação do Partido Pirata a nível global está disponível em http://en.wikipedia.org/wiki/List_of_ Pirate_Parties. Acesso em: 05 fev. 2015.
} 
democracia. A dilatação das ações programáticas recebeu impulso através da acolhida realizada pelos membros às potencialidades instrumentais das tecnologias digitais na promoção de uma experiência efetiva do exercício político. Desta forma, passaram a defender propostas conjuntas orientadas em promover o livre acesso às informações dos atos públicos a fim de permitir a fiscalização e a abertura pública de todos os processos que envolvam o Estado. Como último objetivo, incluíram o compromisso de buscar novas formas para constituir uma democracia líquida definitivamente deliberativa através da utilização da Internet como espaço popular para tomadas de decisão parlamentar.

Nos países que seguiram o exemplo da Suécia, os princípios iniciais mantiveram-se resguardados. Contudo, as propostas passaram a obedecer uma lógica de cariz holística de acordo com os diferentes contextos culturais. A unidade ideológica foi reforçada com a criação do Partido Pirata Internacional, em 2010, e com o Partido Pirata Europeu, em 2014, estabelecendo uma rede imaginária, racionalmente disposta a colocar em prática o seu caráter associativista na luta pelos objetivos comuns (BURKART, 2014). Assim, pode-se pensar que a internacionalização das suas ações reflete o caráter rizomático da rede e integra o quadro dos novos conflitos que impulsionam a formação de novas identidades políticas ${ }^{10}$. Atualmente, o Partido Pirata define a sua política comum a partir de um quadro de ação mais extenso. Embora tenha integrado premissas básicas que também fazer parte do programa partidário de partidos tradicionais, temas apoiados no imaginário tecnológico (abertura, liberdade, transparência, colaboratividade, privacidade e partilha sempre que possivel) orbitam no centro da ideologia que defendem ${ }^{11}$.

${ }^{10}$ Um quadro comparativo elaborado por Andrew Reitemeyer aponta, em caráter exploratório, as afinidades e diferenças das propostas políticas dos diferentes Partidos Piratas. Uma rápida análise do documento comprova que os princípios elementares citados acima permanecem em evidência na maioria dos partidos listados no documento. Disponível em: $<$ http://www.cleopolis.com/PP_comparison_policies.html $>$. Acesso em: 14 abr. 2013.

${ }^{11}$ Em 2015, a política comum dos Partidos Piratas incluía os seguintes pontos: 1) Defender a liberdade de expressão, comunicação, educação; respeito à privacidade dos cidadãos e os direitos civis em geral; 2) Defender a liberdade de fluxo de ideias, conhecimento e cultura; 3) Apoiar politicamente a reforma dos direitos autorais e leis de patentes; 4) Trabalhar de modo colaborativo e participativo com o máximo de transparência; 5) Não aceitar ou adotar políticas de discriminação de raça, origem, crenças ou gênero; 6) Não apoiar ações que envolvem a violência; 7) Usar softwares com códigos abertos, free hardware, Do It Yourself e protocolos abertos sempre que possível; 8) Defender politicamente a construção aberta, participativa e colaborativa de qualquer política pública; 9) Democracia direta; 10) Acesso aberto; 11) Dados abertos; 12) Economia solidária, economia para o bem comum e promoção da solidariedade entre os piratas; 13) Partilhar sempre que possível. Disponível em https:/en.wikipedia.org/wiki/Pirate_ Party, acesso em 10 jan. 2015. 
Do ponto de vista parlamentar, o Partido Pirata da Suécia, o da Alemanha, e recentemente, o da Islândia, representam os casos com algum respeito político formal. No entanto, como partidos marginais, ocupam uma posição relativamente inferior em comparação aos tradicionais. Ainda que permaneçam fora dos círculos de poder político, o ativismo que promovem silenciosamente parece se expandir a partir de ações de reconhecimento social na produção de uma nova agenda dos modos de se fazer política nas sociedades digitais. As intervenções dos eurodeputados do Partido Pirata da Suécia, Christian Engström e Amelia Andersdotter, em favor da reforma do copyright e da abertura pública, por exemplo, das reuniões secretas e negociações fechadas acerca do ACTA que eram realizadas no Parlamento Europeu, simbolizam os investimentos ideológicos desses atores na luta por um sociedade baseada no imaginário reticular. Sinaliza também a sua gradativa aceitação política. Veja o caso da nomeação de Julia Reda, eleita nas eleições européias de 2014 pelo Partido Pirata da Alemanha, como parlamentar responsável por conduzir a elaboração de um relatório sobre a aplicação da Diretiva 2001/29 (conhecida como "Directiva Infosoc") que intenciona harmonizar alguns aspectos das leis de direitos autorais e dos direitos conexos no âmbito europeu. Ainda no campo da emergência do movimento no cenário parlamentar, os resultados de uma sondagem pública sobre o apoio popular aos partidos políticos realizadas em março de 2015 na Islândia colocaram o Partido Pirata liderado pela deputada Birgitta Jónsdóttir ${ }^{12}$ no topo da lista ao alcançarem 23,9\% da intenção de voto dos islandeses ${ }^{13}$.

Ao olhar para a trajetória e para as estruturas de sentido do Partido Pirata compreende-se que o sucesso das redes, nomeadamente o da Internet, deve-se tanto pela sua qualidade técnica na maximização do lucro das empresas que exploram o universo digital e que por ela se organizam de modo globalizado, com também pela instrumentalidade simbólica que ela proporciona na formação de novas dinâmicas sociais, novas formas associação e novas formas da vida política a nível local, nacional e níveis transnacionais. Enquanto rede, ela pode ser interpretada como um símbolo de liberdade e progresso econômico, conforme

\footnotetext{
12 Disponível em: http://www.visir.is/the-pirate-party-is-now-measured-as-the-biggest-party-in-iceland/ article/2015150318848, Acesso em 19 mar. 2015.

13 O termo "pirata" é utilizado pelos integrantes dos Partidos Piratas para identificar os seus respectivos membros. No texto, a terminologia tem o mesmo efeito. Apesar das ambiguidades semânticas e do caráter pejorativo da palavra na cultura contemporânea, o uso realizado pelos membros do Partido Pirata pode ser entendido como uma ação afirmativa para demarcar um lugar de existência no campo da política partidária.
} 
demonstrou Musso (2013), como um meio de dominação, aprisionamento e vigilância, e também pode ser admitida como dispositivo de agência, autonomia e de protesto político.

Se, de um lado, ela é incorporada como subsídio para o desenvolvimento de uma economia saturada onde a informação e o conhecimento formam a infraestrutura para o reajuste do capitalismo, fundamentando, por sua vez, a afirmação de políticas econômicas e de mecanismos legais de proteção de monopólios, por outro lado, a sua difusão para o espectro da vida prosaica - exemplificada, principalmente a partir dos anos de 1990 por novos movimentos sociais e revoltas globais que levam a chancela da Internet como catalisadora de suas ações (DI FELICE, 2013) — reitera o caráter diversificado que as matizes mitológicas da rede proporcionam ao imaginário social (MUSSO, 2004; POSTIGO, 2012).

Hoje, não é possível uma análise da Internet que desconsidere as animosidades coletivas e as subjetividades tecnológicas que se formaram na vida quotidiana a partir da sua intensificação como um recurso fundamental da luta política (HANDS, 2011). Da mesma forma, seria ingenuidade olvidar-se do parasitismo das empresas que se beneficiam das ideologias políticas e das esperanças militantes orientadas, exclusivamente, sobre a função emancipatória da tecnologia. As atuais disputas pela dominação da rede representadas, por exemplo, por intensos lobbies partidários, manuais de comportamento e acordos internacionais interessados no fomento de estruturas jurídicas que permitam o seu total controle, a sua demarcação geopolítica e a sua censura, não retiram nem invalidam a práxis política sobrevinda da sua utilização. Tampouco, não a afirma como resultado competente do prognóstico de diversos autores que para ela apontaram a expectativa de renovação democrática do mundo globalizado. Embora a ação de agentes sociais seja, de algum modo, efetiva no campo do ativismo, as assimetrias do uso da Internet no mundo ainda continuam orientadas pela exploração mercantil da sua qualidade técnica, o que quer dizer que o utilizador ainda depende de um acesso oneroso e pago a infraestruturas que continuam nas mãos da elite das empresas de telecomunicações.

Em certa medida, pensando sobre a relação geral entre "estrutura" e "agência" (ARCHER, 1995), tais condicionamentos estruturais tendem a atuar como elementos de desaceleração das capacidades criativas dos sujeitos através de uma prática que subestima a variedade interventiva que desses agentes pode emergir tanto do meio para o sujeito como do sujeito para ele próprio. Entretanto, as experiências de autonomia que dela decorrem intensificam a sua acepção como artefato cultural orientado por uma relação emocional que, por sua vez, alimenta a sua essencialidade. E assim, a polissemia da rede permite confrontar as visões 
dicotômicas entre o objetivismo e o subjetivismo a partir de uma perspectiva que a admite não simplesmente como objeto técnico moldado por esquematismos funcionalistas (de cariz política neutralizadora da ação), em que os sujeitos são apenas um suporte de maximização dos monopólios, mas como instrumento para performances qualitativas que se erguem no imaginário coletivo menos pela sua qualidade técnica rizomática e mais pelo caráter social e histórico das formas criativas das interações sociais que antecedem a sua existência.

Apesar desta perspectiva ser tentadora, implica dizer que ela só pode se afirmar como possibilidade analítica se for interpretada por uma via que se distancia das unilateralidades sociológicas preocupadas em enquadrar e estruturar, de modo dualístico e restrito, a historicidade produtiva de tais interações e se aproxima de uma análise praxiológica centrada nas razões e nos propósitos das conjugações e reflexividades que os agentes sociais realizam no sentido de influir, seja de modo intencional ou não, nos fluxos sociais que esboçam vida quotidiana. Esta habilidade em transformar a prática, segundo a acepção de Giddens (1979), depende de instrumentos que capacitem o agente social, ou seja, de uma "estrutura", entendida não a partir da sua forma histórica de designar as relações de poder, mas pela sua função mobilizadora.

A pirataria digital nas redes tecnológicas é paradigmática nesse caso. Integrada ao campo evolutivo da regulação da Internet, a prática pode se interpretada tanto como uma forma de apropriação nociva, nos casos em que ela é feita com intenções precisamente criminosas, como também pode ser descrita pelo viés do consumismo hedônico sem qualquer fim lucrativo, como defendeu Lessig (2004). Apesar das ambiguidades que incidem sobre a prática, a principal chave para desencadear a sua função política refere-se à quebra de monopólios. Nos dois casos, embora o segundo seja admitido como um novo modo de distribuição de conteúdo (LESSIG, 2004) e, portanto, algo que deveria ser promovido pela lei como um recuso saudável ao desenvolvimento cultural dos indivíduos, a prática reincide como um ato legalmente constituído como crime punível, sendo enquadrada nos termos legais que regem os direitos autorais, a propriedade intelectual e as patentes. No entanto, perante a transformação da cultura como campo de batalha e a conversão social do acesso à Internet como um direito humano ${ }^{14}$ e as variadas formas de eletroconsumo que dela

\footnotetext{
${ }^{14}$ Através de um relatório elaborado pelo Conselho de Direitos Humanos da Organização das Nações Unidas (ONU) e o site Mashable, a ONU defendeu o acesso à rede de computadores como um direito humano fundamental para o desenvolvimento social dos indivíduos e recomendou aos países signatários a revisão das respectivas leis de direitos autorais no sentido de promoverem um acesso equilibrado e sem prejuízo às sociedades. Disponível em: www2.ohchr.org/english/bodies/hrcouncil/docs/17session/A.HRC.17.27_en.pdf, Acesso em: 10 jan. 2014.
} 
emergem, os conflitos tendem a se acentuar ainda mais devido à facilidade de reprodução e circulação da informação digital (BOYLE, 2008).

Partidos Piratas espalhados pelo planeta integram o quadro evolutivo e impulsionador que a tecnologia da Internet providencia aos agentes sociais nos processos de interação simbólica com os produtos e bens que emergem da digitalização da informação. Ao mesmo tempo em que ela permite o reajuste do capitalismo através das diversas formas de consumos, tanto ao nível físico como no âmbito do seu consumo imaterial, as evasividades multitudinárias (NEGRI \& HARDT, 2004) que dela emergem, emparcelam a questão da propriedade intelectual uma vez que a lógica da política de liberalização dos fluxos altera a interação do utilizador com o conceito de propriedade privada. Na rede tudo está acessível. Se ela é quem dá corpo à sociedade contemporânea e se a informação dá a vida que nela circula, ninguém pode ser dono da rede, ninguém pode ser proprietário do que nela navega. Para conter as reflexividades reticulares (partilhar é cuidar) que se espelham nos comportamentos dos utilizadores, a lógica de privatização do conhecimento, da cultura e da informação tem colaborado, de modo antagônico, com a criação de políticas de controle e cerceamento da privacidade e da liberdade de uso da Internet. Todavia, tem reafirmado também novos campos de combates políticos (partilhar é lutar) aparentemente empenhados na conceptualização da rede de modo híbrido, ou seja, como espaço público para a ação política e como espaço privado para a atividade social. A ação oposicional que os piratas propõem no âmbito da reforma da gramática jurídica sobre as leis da propriedade intelectual e dos direitos autorais reverbera como práticas de resistência contra a colonização da Internet e a privatização da informação a partir de um discurso que defende a urgência de tornar a rede um espaço livre e aberto.

\section{Conclusão}

Embora a Internet tenha sido cooptada como meio otimizado para maximização de lucros, esses movimentos sociais parecem inaugurar novos contornos do protagonismo social ao serem instaurados a partir de um esboço de negação das relações monopolistas e territoriais da informação. A ação oposicional que o Partido Pirata propõe no âmbito da reforma da gramática jurídica sobre as leis da propriedade intelectual e dos direitos autorais 
reverbera como práticas de resistência contra a colonização da Internet e a privatização da informação a partir de um discurso que defende a urgência de tornar a rede um espaço livre e aberto (BURKART, 2014). Nesta ordem de pensamento, o seu emergir fundamenta um momento político excepcional do chamado ciberativismo (DI FELICE, 2013). Tutelado pela defesa da Internet como lugar simbólico da liberdade, da transparência, da partilha, do associativismo, da democracia e da igualdade, o Partido Pirata não só reitera o caráter libertário e técnico-utópico que outrora ancorou as visões mitológicas acerca da rede, como também, inaugura uma mudança na rota histórica dos movimentos ciberativistas a partir da institucionalização partidarista destas utopias.

Seguindo o raciocínio de Honneth (2009), a ação desses atores parece primar pela reparação da exclusão estrutural de direitos fundamentais (autonomia, privacidade, acesso à cultura) a partir de uma prática que sai do horizonte das intenções individuais passando a ser a base de um movimento coletivo e ampliado. Nesta perspectiva, a luta comum por reconhecimento que procuram estabelecer no imaginário político aparenta ser uma reivindicação que ultrapassa o mero exercício partidário na solidificação de um poder (MCDONALD, 1999, p. 155; HONNETH, 2009). Ao invés de se ancorarem em formalidades parlamentares por meio de um plano setorizado de governo orientado para a construção de uma política privada, a centralidade da sua prática no campo da Internet expande o universo da sua proposição e despolariza o seu campo de atuação na medida em que utilizam tanto a natureza homogênica da lei no processo de planificação e incriminação das práticas (somos todos piratas) que são entendidas como ameaça aos avanços econômicos, bem como o simbolismo provido pela rede na promoção de uma comunidade transnacional de pares (estamos todos conectados). Se a rede segrega, vigia e exclui, para os piratas, ela agrega, organiza e empodera.

A política de tais atores parece se exteriorizar não como um ato de resignação, mas de confrontação com a higiene e com os limites da norma como postulado ambíguo da gestão de ilegalismos intoleráveis, que ela diferencia - a par dos que ela permite como privilégios da classe dominante - a fim de formalizá-los, proibi-los, isolá-los e torná-los objetos de domínio. Seguindo a proposta de Honneth (2009, p. 259), o engajamento desse movimento reitera a ação agêntica dos sujeitos na medida em que a sua imagem como sujeito passivo e paralisado é suprimida por meio de uma autorrelação nova e de uma eticidade positiva proporcionadas pelas experiências morais de desapontamento das expectativas normativas e de desrespeito aos monopólios digitais. De modo reverso, o 
pesadelo tecnológico volta a ser o sonho da utopia pirata. Nesse aspecto, o envolvimento político de indivíduos organizados por subjetividades tecnológicas através da rede marca o surgimento institucional de um grupo, quiçá de uma minoria politicamente especializada, que imagina o futuro das sociedades digitais a partir da renovação da política da Internet. Isto significa a elaboração de um novo mapa político com trilhas e caminhos que reforce ciberliberdades, garanta direitos digitais, contradiga o capitalismo informacional e, acima de tudo, crie uma marca identitária e uma nova categoria política. Se a rede legifera as instâncias de poder para alguns, para os piratas, ela subvenciona a criação de uma nova rota para a resiliência digital, para a resistência política e para a existência social. O seu itinerário, apesar de ser silencioso e estudado de modo periférico, se não representa a qualificação final do empreendedorismo político na luta pela dominação da Internet, sinaliza uma vontade utópica e comum na busca pela restituição da agência coletiva na medida em que a rede, nas suas diversas metamorfoses apontadas por Musso (2004) e Mattelart (1994), pode ser utilizada de modo polissêmico, quer como um instrumento de exploração comercial quer, em sentido aparentemente antípoda, como espaço crítico para a afirmação de identidades, para o reconhecimento solidário, para a estima mútua e, acima de tudo, para a vexação pública dos artifícios jurídicos que a sustentam.

\section{Referências}

ARCHER, Margaret. Culture and agency. Cambridge: Cambridge University Press, 1995.

ANTOUN, Henrique; MALINI, Fábio. @internet e \#rua: ciberativismo e mobilização nas redes sociais. Porto Alegre: Sulina, 2013.

ARROW, Kenneth J. The economics of information. Cambridge, Massachusetts: Harvard University Press, 1984.

BARLOW, John Perry. A declaration of the independence of cyberspace. 1996. Disponível em: < https://projects.eff.org/ barlow/Declaration-Final.html $>$. Acesso em:12 abr. 2014.

BATES, Benjamin J. Information as an economic good: sources of individual and social value. In: MOSCO, Vincent; WASKO, Janet. (Orgs.). The political economy of information. The University of Wisconsin Press: London, p. 76-94, 1988. 
BORGMANN, Albert. Holding on to reality: the nature of information at the turn of the millennium. Chicago, London: The University of Chicago, 1999.

BOYLE, James. The public domain: enclosing the commons of the mind. New Haven, London :Yale Univ Press, 2008.

BRAGA, Ruy; ANTUNES, Ricardo. Infoproletários: degradação real do trabalho virtual. São Paulo: Boitempo Editorial, 2009.

BRAMAN, Sandra. Defining information: an approach for policymakers. Telecommunications Policy, n. 13, p. 233-242, 1989.

BURKART, Patrick. Pirate Politics: the new information policy contests. The Information Society Series. Cambridge/ London: The MIT Press, 2014.

CASTELLS, Manuel. A sociedade em rede. 8a ed. Vol. 1. Rio de Janeiro: Paz e Terra, 2005. . Internet e sociedade em rede. In: MORAES, Dênis de. (org) Por uma outra comunicação. Rio de Janeiro: Record, p. 255-287, 2004.

DANTAS, Marcos. Information and labor in contemporary capitalism. Lua Nova: Revista de Cultura e Política, n. 60, p. 05-44, 2003.

DI FELICE, Massimo. Ser redes: o formismo digital dos movimentos net-ativistas. Matrizes, Ano 7, n. 2, jul./dez. 2013, p. 49-71, 2013.

ERLINGSSON, Gissur Ó.; PERSSON, Mikael. The swedish Pirate Party and the 2009 european parliament election: Protest or issue Voting? Politics, n. 31, v.3, p. 121-128, 2011.

FALKVINGE, Rick. Swarmwise: the tactical manual to changing the world. North Charleston: CreateSpace Independent Publishing Platform: 2013.

FLORIDI, Luciano; SANDERS, J.W. Internet ethics: The constructionist values of homo poieticus. In: CAVALIER, Robert J. (Org.). The impact of the internet on our moral lives. New York: State University of New York Press, p. 195-214, 2005.

FUCHS, Christian. Digital labour and Karl Marx. New York: Routledge, 2014.

GARCIA, José Luís. Biotecnologia e biocapitalismo global. Análise Social, XLI, n. 181, p. 981-1009, 2006.

GIDDENS, Anthony. Central problems in social theory: action, structure, and contradiction in social analysis. Berkeley: University of California Press, 1979.

GORZ, André. L'immatériel. Connaissance, valeur et capital. Paris: Editions Galilée, 2003. 
HANDS, Joss.@Is for activism: dissent, resistance and rebellion in a digital culture. London; New York: Pluto Press, 2011.

HONNETH, Axel. Luta por reconhecimento: a gramática moral dos conflitos sociais. 2a ed. São Paulo: Editora 34, 2009.

JORDAN, Tim. Information politics: liberation and exploitation in the digital society. Pluto Press, 2015.

LEMOS, André. Cidade-ciborgue: A cidade na cibercultura. In: LEMOS, André (Org.). Cibercidade II: Ciberurbe. A cidade na sociedade da informação. Rio de Janeiro: E-papers Serviços Editoriais, p. 11-34, 2005.

LESSIG, Lawrence. Free culture: The nature and future of creativity. New York: Penguin Press, 2004.

MACFARQUHAR, Larissa. Requiem for a dream. The New Yorker. Disponível em: <http://www.thebuddhasaidiamawake.com/wp-content/uploads/2014/01/ Larissa-MacFarquhar-The-Tragedy-of-Aaron-Swartz-The-New-Yorker.pdf $>$. Acesso em: 20 mar. 2015.

MARTINS, Hermínio. Experimentum humanum. Civilização tecnológica e condição humana. Lisboa: Relógio D’Água, 2011.

MATTELART, Armand. A invenção da comunicação. Colecção: Epistemologia e Sociedade 42. Lisboa: Instituto Piaget, 1994.

História das teorias da comunicação. São Paulo: Loyola, 2000.

MCDONALD, Kevin. Struggles for subjectivity: identity, action and youth experience. Cambridge: Cambridge University Press, 1999.

MERKLÉ, Pierre. Sociologie des réseaux sociaux. Paris: La Découverte, 2004.

MIEGEL, Fredrik; OLSSON, Tobias. From pirates to politician: the story of the swedish file sharers who became a political party. In: CARPENTIER, Nico; PRUULMANN-VENGERFELDT, Pille; NORDENSTRENG, Kaarle; HARTMANN, Maren; VIHALEMM, Peeter; CAMMAERTS, Bart; NIEMINEN, Hannu; OLSSON, Tobias. (Orgs.). Democracy, Journalism and Technology: New Developments in an Enlarged Europe. Tartu: Tartu University Press, p. 203-217, 2008.

MUSSO, Pierre. La symbolique du réseau. Quaderni, n. 38, v. 1, p. 69-98, 1999. . Critique des réseaux. Paris: Presses Universitaires de France - PUF, 2003. 
. A filosofia da rede. In: PARENTE, André (Org.). Tramas da rede - Novas dimensões filosóficas, estéticas e políticas da cognição. Porto Alegre: Sulina, p. 17-38, 2004.

. Network ideology: from saint-simonianism to the internet. In: International Conference of the Society for Philosophy and Technology. 4-6 de Julho de 2013. ISEG: Lisboa, 2013.

NEGRI, Antonio; HARDT, Michel. Império. Rupturas 1. Lisboa: Livros do Brasil, 2004.

POSTIGO, Hector. The digital rights movement: the role of technology in subverting digital copyright. Cambridge/London: The M.I.T. Press, 2012.

RIFKIN, Jeremy. The age of access: the new culture of hypercapitalism where all of life is a paid-for experience. New York: Tarcher/Putnam, 2000.

SCHILLER, Dan. Digital capitalism: networking the global market system. Massachussets, London: The MIT Press, 2000.

. How to think about information. Illinois: University of Illinois Press, 2007.

Digital depression: information technology and economic crisis. 1st Edition edition. Urbana, Chicago: University of Illinois Press, 2014.

SCHOLZ, Trebor. Digital labor: The internet as playground and factory. New York: Routledge, 2013.

SCIANNAMBLO, Mariacristina. The internet between politics and the political: The birth of the Pirate Party. In: FREDRIKSSON, Martin; ARVANITAKIS, James (Orgs.). Piracy: leakages from modernity. Sacramento, CA: Litwin Books, p. 177-194, 2014.

SIMS, Nancy. Library licensing and criminal law: The Aaron Swartz case. In: College \& Research Libraries News, v. 72, n. 9, p. 534-537, 2011.

SFEZ, Lucien. Técnica e ideología: un juego de poder. Coyoacán /Buenos Aires: Siglo XXI, 2005.

SUBTIL, Filipa. Comunicação, redes e capitalismo digital. In: Trajectos. Revista de Comunicação, Cultura e Educação, n. 10, p. 103-112, 2007.

SWARTZ, Aaron. Guerilla Open Access Manifesto. 2008. Disponível em: < https://archive. org/stream/GuerillaOpenAccessManifesto/Goamjuly2008_djvu.txt>. Acesso em: 12 abr. 2014.

WELLMAN, Barry; BERKOWITZ, Stephen D. Introduction: Studyng social structures. In: WELLMAN, Barry; BERKOWITZ, Stephen D. (Orgs.). Social structure. A network approach. Cambridge: Cambridge University Press, p. 1-14, 1991. 